University of Nebraska - Lincoln

DigitalCommons@University of Nebraska - Lincoln

Publications, Agencies and Staff of the U.S.

Department of Commerce

U.S. Department of Commerce

2011

\title{
A synergetic use of satellite imagery from SAR and optical sensors to improve coastal flood mapping in the Gulf of Mexico
}

\author{
Naira Chaouch \\ City University of New York, nchaouch@ccny.cuny.edu \\ Marouane Temimi \\ City University of New York \\ Scott Hagen \\ University of Central Florida \\ John Weishampel \\ University of Central Florida \\ Stephen Medeiros \\ University of Central Florida \\ See next page for additional authors
}

Follow this and additional works at: https://digitalcommons.unl.edu/usdeptcommercepub

Part of the Environmental Sciences Commons

Chaouch, Naira; Temimi, Marouane; Hagen, Scott; Weishampel, John; Medeiros, Stephen; and Khanbilvardi, Reza, "A synergetic use of satellite imagery from SAR and optical sensors to improve coastal flood mapping in the Gulf of Mexico" (2011). Publications, Agencies and Staff of the U.S. Department of Commerce. 251.

https://digitalcommons.unl.edu/usdeptcommercepub/251

This Article is brought to you for free and open access by the U.S. Department of Commerce at DigitalCommons@University of Nebraska - Lincoln. It has been accepted for inclusion in Publications, Agencies and Staff of the U.S. Department of Commerce by an authorized administrator of DigitalCommons@University of Nebraska - Lincoln. 


\section{Authors}

Naira Chaouch, Marouane Temimi, Scott Hagen, John Weishampel, Stephen Medeiros, and Reza

Khanbilvardi 


\title{
A synergetic use of satellite imagery from SAR and optical sensors to improve coastal flood mapping in the Gulf of Mexico
}

\author{
Naira Chaouch, ${ }^{1 *}$ Marouane Temimi, ${ }^{1}$ Scott Hagen, ${ }^{2}$ John Weishampel, ${ }^{2}$ \\ Stephen Medeiros ${ }^{2}$ and Reza Khanbilvardi ${ }^{1}$ \\ ${ }^{1}$ NOAA-CREST/The City University of New York, New York, NY, USA \\ ${ }^{2}$ University of Central Florida, Orlando, FL, USA
}

\begin{abstract}
:
This work proposes a method for detecting inundation between semi-diurnal low and high water conditions in the northern Gulf of Mexico using high-resolution satellite imagery. Radarsat 1, Landsat imagery and aerial photography from the Apalachicola region in Florida were used to demonstrate and validate the algorithm. A change detection approach was implemented through the analysis of red, green and blue (RGB) false colour composites image to emphasise differences in high and low tide inundation patterns. To alleviate the effect of inherent speckle in the SAR images, we also applied ancillary optical data. The flood-prone area for the site was delineated a priori through the determination of lower and higher water contour lines with Landsat images combined with a high-resolution digital elevation model. This masking technique improved the performance of the proposed algorithm with respect to detection techniques using the entire Radarsat scene. The resulting inundation maps agreed well with historical aerial photography as the probability of detection reached $83 \%$. The combination of SAR data and optical images, when coupled with a high-resolution digital elevation model, was shown to be useful for inundation mapping and have a great potential for evaluating wetting/drying algorithms of inland and coastal hydrodynamic models. Copyright (C) 2011 John Wiley \& Sons, Ltd.
\end{abstract}

KEY WORDS intertidal flood mapping; multisensor; Radarsat; Landsat; image classification

Received 26 May 2011; Accepted 10 August 2011

\section{INTRODUCTION}

Coastal regions, particularly in the Gulf of Mexico area, are often subject to major flooding because of significant tidal variations or extreme meteorological events and ocean surges. It is critical to accurately delineate the inundated areas to promptly assess the associated damages and understand the hydrodynamic processes in these coastal regions. However, the relatively flat topography in the region fosters the lateral expansion of sea water and makes the accurate delineation of inundated areas difficult. The standard use of aerial photography and in situ observations can only lead to a local and limited assessment of the effect of change in water level in coastal regions. Hydrodynamic models can be used, but if they are not properly forced and initialised, they may lack accuracy and robustness. In this regard, remote sensing-based techniques are a preferable alternative for flood detection and monitoring as they are highly resolved temporally and capture a large coverage area at reasonable spatial resolution (Schumann et al., 2009).

Flooded areas were first delineated from space using optical imagery (Rango and Salomonson, 1974; Wang et al., 2003) on the basis of the contrast between the reflectances of water and dry soil in the visible and near infrared

*Correspondence to: Chaouch, Naira, Civil Engineering, NOAA-CREST/ The City University of New York, The City College, Steinman Hall, New York, NY 10031.

E-mail: nchaouch@ccny.cuny.edu domains. Images acquired in these wavelengths (i.e. visible and near infrared) are usually at high or moderate spatial resolution, which ranges from $30 \mathrm{~m}$ to $1 \mathrm{~km}$ depending on the sensor's configuration. They are therefore very appropriate for flood monitoring. However, these images are only useful when the scene is captured cloud free. However, flood events usually coincide with cloudy conditions, limiting the usefulness of images in the visible and near infrared wavelengths.

On the other hand, active microwave sensors such as ERS, JERS, Radarsat 1 and Envisat provide an attractive alternative. They are 'all sky' capable and not dependent on daylight. Lower frequencies, specifically the L-band $(1.4 \mathrm{GHz})$ that is planned to be onboard the upcoming NASA SMAP mission, are more appropriate for soil moisture and flood monitoring applications (Hess et al., 1995; Bourgeau-Chavez et al., 2001) as they are less sensitive to cloud and vegetation cover. Radar-based approaches to delineate and monitor coastal flooding fall into one of two categories. Approaches in the first category make use of a single radar image that is clustered through the identification of different classes from the change in the spatial pattern of the backscatter (Kasischke and BourgeauChavez, 1997; Townsend, 2001; Bonn and Dixon, 2005; Kwoun and Lu, 2009). The second category includes approaches that are based on the change detection concept that compares before and after flood images and determines the differences in numerical values of each pixel (Tanis et al., 1994; Kiage et al., 2005). Inundated pixels should be identifiable as their backscatter should substantially drop 
when the land is inundated with respect to its values before the flood.

Despite the high sensitivity of the radar signal to liquid water and its potential in delineating inundated terrains, its automated use to systematically detect flooded areas is not straightforward with only very few notable exceptions recently (Martinis et al., 2009; Matgen et al., 2011) because of the inherent speckle noise present in radar images. Speckle noise that is randomly introduced in radar data reduces the interpretability of the image and limits the performance of the classification method. Whether a single or two channel (i.e. change detection)-based approach is selected, appropriate filtering is necessary before the use of the images to reduce the speckle noise. However, in the case of change detection approaches, the areas where the changes have occurred tend to be highlighted.

Change detection between different dates can be carried out by calculating (i) the difference between two images (Cihlar et al., 1992; Tanis et al., 1994; Kiage et al., 2005), (ii) the normalised difference index (Badji and Dautrebande, 1997; Nico et al., 2000), (iii) the ratio of two images (Dekker, 1998; Bazi et al., 2005), (iv) the interferometric coherence information (Nico et al., 2000) or (v) the multitemporal false colour composite image (Badji and Dautrebande, 1997; Kiage et al., 2005). Under the category of change detection-based approaches, pixels that exhibit changes in their backscatter can be classified depending on the magnitude of the change using predetermined thresholds, which can be determined iteratively through a trial and error procedure (Bovolo and Bruzzone, 2005) or through an automated process (Bazi et al., 2005). The performance of these approaches depends largely on the accuracy of the determined thresholds that are usually static in space and time despite the significant variability of the backscatter, which may lead to misidentifying pixels. This underscores the importance of using additional sources of observation along with the radar to improve the performance of the clustering techniques. In this perspective, images in the visible and infrared wavelengths are a good option because their geographic extent and spatial resolution are on the order of those in radar images.

This methodology that exploits multisatellite imagery was investigated, and the combination of images from multiple sensors to improve the classification accuracy was tested. Multisource image fusion was first applied for land use classification and image segmentation (Solberg et al., 1994; Macri-Pellizzeri et al., 2002). In the context of flood monitoring and wetland studies, multisource, optical remote sensing, radar and GIS data were considered to reduce the error in flood mapping obtained from the analysis of a single channel (Tholey et al., 1997; Wang, 2002). Optical remote sensing and radar data were combined to benefit from the complementary information from both sources as optical remote sensing data provide information on the multispectral reflectivity of the ground target whereas radar data depend on their texture. Multisensor image fusion was performed at three different processing levels, pixel level, feature level and decision level, using a wide variety of techniques (Pohl and Van Genderen, 1998). For wetland and flood monitoring, Toyra et al. $(2002 ; 2005)$ used the augmented vector approach to combine radar data and optical images from Landsat or SPOT as if they were obtained by one sensor. To extract flooded area and water body, Sun et al. (2007) considered the principal components analysis and the intensity, hue and saturation method to combine infrared Landsat bands and radar data. Brivio et al. (2002) used topographic data in combination with radar data to extract flooded areas at their peak. Dey et al. (2008) considered a decision fusion approach to combine classification results from Radarsat and Landsat data to distinguish between permanent water and flood regions. Li and Chen (2005) applied a decision rule technique using Radarsat 1, Landsat 7 and DEM data for wetlands mapping. Their approach consists of combining different products derived from separate sources of information instead of merging them to develop a single ultimate product.

This study proposes to improve the delineation of flooded areas between semi-diurnal low and high water conditions in the northern Gulf of Mexico using a combination of optical and active microwave images along with topographic data. Optical and topographic data are used to reduce the effect of the inherent speckle noise in the SAR images and to allow for better segmentation of radar data. The proposed technique was tested using aerial photography.

\section{METHODOLOGY}

\section{Study areas}

Apalachicola Bay is located in Franklin County on Florida's panhandle. The Apalachicola River generally runs in a southerly direction before discharging into the bay near the city of Apalachicola and forms the boundary between Franklin and Bay counties and also the Eastern and Central Time Zones. The seaward side of Apalachicola Bay is bounded by St. George Island. In colloquial usage, the Apalachicola area runs from St. Joseph Bay east to Ochlockonee Bay and contains parts of Wakulla, Franklin and Bay counties. The coastal areas within the Radarsat scene boundary used in this study contain parts of Franklin, Wakulla and Jefferson counties.

The terrain in this region consists primarily of low-lying coastal forest and wetlands with elevations ranging from below mean sea level to greater than $30 \mathrm{~m}$ NAVD88. The land cover in the region is predominantly palustrine wetlands of various subtypes, evergreen forest and grassland/herbaceous (Homer et al., 2007). Some areas classified as developed with the major population centres are Apalachicola, Eastpoint and Carrabelle.

Figure 1 presents the geographic location and coverage for the study area as well as the areas of validation. These scenes were selected viewing the aerial photos availability. They cover the Rattlesnake Cove/Goose Island section of St. George Island and Ochlockonee Bay/Alligator Point. 


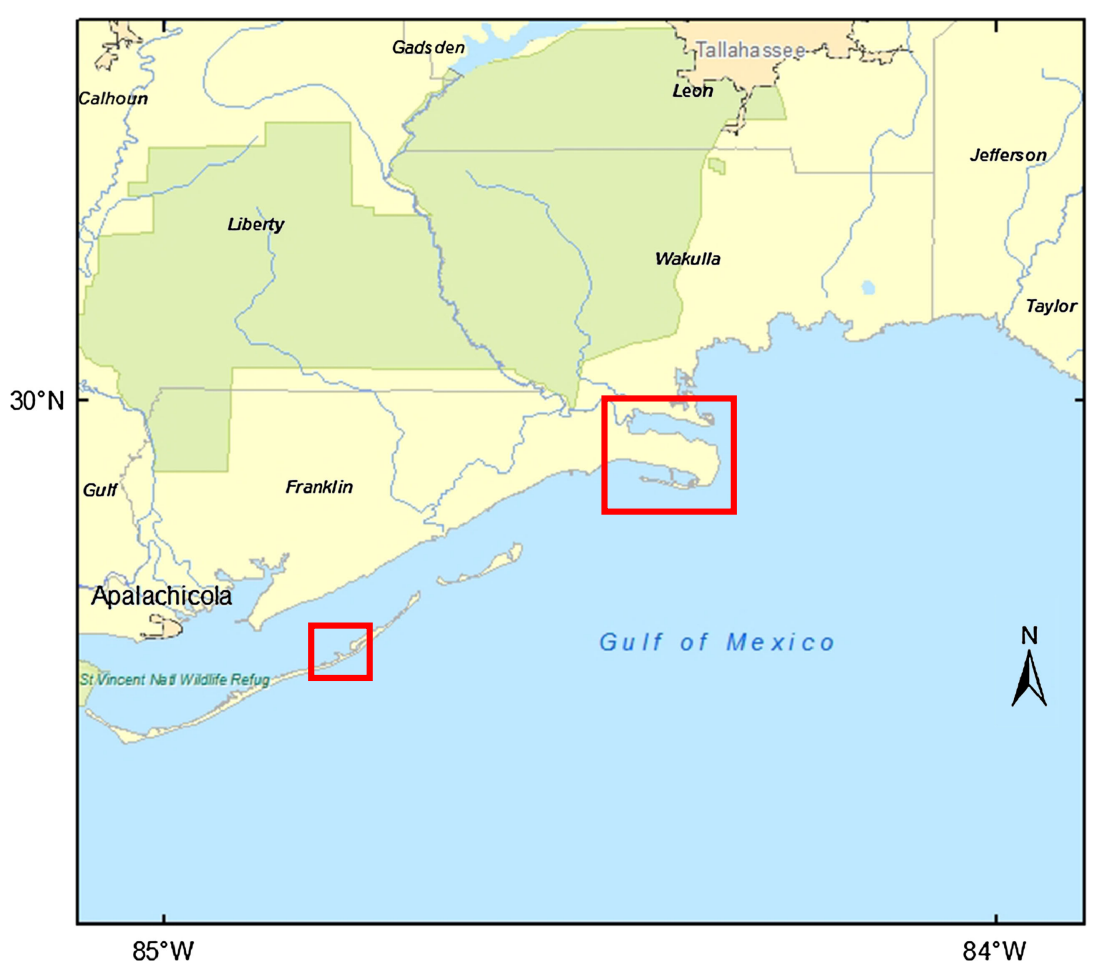

Figure 1. Study areas. Red boxes: areas used for validation

\section{Data sets}

The proposed approach combines data from different sources, namely, optical images, DEM data and Radarsat 1 images. Radarsat 1 satellite operates at the $\mathrm{C}$ band $(5.3 \mathrm{GHz})$ wavelength and transmits and measures energy at the $\mathrm{HH}$ polarisation. It is in a sun synchronous orbit and operates on a 24-day revisit cycle. For this study, four Radarsat 1 images in standard mode (ST) were obtained from the Alaska Satellite Facility (http://www.asf.alaska. edu/). The standard mode is one of the seven beam modes available from Radarsat 1 having a swath width of $100 \mathrm{~km}$. Their nominal spatial resolution is $25 \mathrm{~m}$ with a pixel size of $12.5 \times 12.5 \mathrm{~m}$. The products are delivered as four look amplitude images in the UTM projection referenced to the WGS 84 horizontal datum. Radarsat 1 standard mode is acquired in seven beam positions referred as ST1 to ST7 depending on the incidence angle values. For Apalachicola area, ST2 to ST5 images are available. Because smaller incidence angles are more suitable for flood detection (Wang et al., 1995), ST3 images acquired with incidence angles of $30^{\circ}$ to $37^{\circ}$ were considered for this study. They meet the needs of the study by providing short temporal and spatial baselines. Images taken on 20 January 2003, 17 September 2003, 3 March 2004 and 25 July 2004 around 11:40 h GMT were imported. The image taken on 3 March 2004 corresponds to the lowest tide condition (see Table I).

A cloud-free Landsat 7 ETM + image taken on 2 February 2003 was obtained from the US Geological Survey Web site. Its original spatial resolution was $30 \mathrm{~m}$. The Landsat image was first resampled and regridded to the UTM projection and WGS 84 datum with a pixel size of $12.5 \mathrm{~m}$ to match the Radarsat images. The selected Landsat image corresponds to the lowest water level observed, $-0.459 \mathrm{~m}$. It coincides with low tide conditions (see Figure 2). The water level observations shown in Figure 2 at the Apalachicola station are imported from the NOAA Tides and Currents archive (http://tidesandcurrents. noaa.gov/). They were used to determine the tidal conditions at the acquisition time of the Radarsat images. Water levels are measured with respect to the NAVD 88 datum.

The primary source of topographic data was bare-earth LiDAR products acquired in the summer 2007. The DEM derived from these LiDAR data is reported to be accurate to within $0.67 \mathrm{~m}$ RMSE horizontally and $0.18 \mathrm{~m}$ vertically. These data are delivered gridded to $1.22 \mathrm{~m}$ resolution. In the areas along the coastline and offshore, bathymetry data from the National Geophysical Data Center along with National Ocean Service navigational charts are used to define the surface. In the upriver sections of the study area, channel cross sections were used to augment the topographical data.

Table I. Observed water levels and wind speed

\begin{tabular}{lcccc}
\hline $\begin{array}{l}\text { Radar } \\
\text { acquisition } \\
\text { date }\end{array}$ & $\begin{array}{c}\text { 20 January } \\
2003\end{array}$ & $\begin{array}{c}\text { 17 September } \\
2003\end{array}$ & $\begin{array}{c}\text { M March } \\
2004\end{array}$ & $\begin{array}{r}25 \text { July } \\
2004\end{array}$ \\
\hline $\begin{array}{l}\text { Water } \\
\text { level }(\mathrm{m})\end{array}$ & -0.064 & 0.24 & -0.24 & 0.278 \\
$\begin{array}{l}\text { Wind } \\
\text { speed }(\mathrm{m} / \mathrm{s})\end{array}$ & 1.1 & 4.3 & 1.1 & 2.3 \\
\hline
\end{tabular}




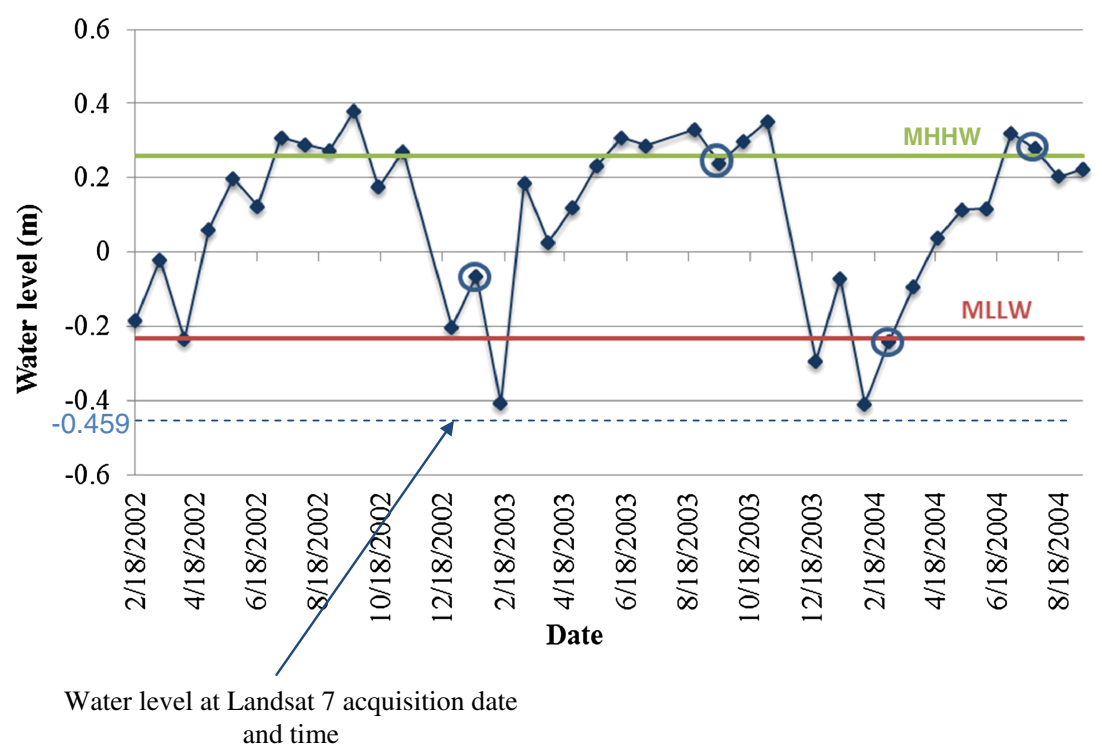

Figure 2. Water level observations (NAV Datum) at Radarsat 1 acquisition time in Apalachicola station (blue circles correspond to the selected Radarsat 1 scenes)

We used historic aerial photographs of Franklin County from 2006 and 2010 as another source of validation. These images with 0.3-m spatial resolution were obtained through the Florida Aerial Photography Archive Collection, which were made available through the Florida Department of Transportation Internet site. Although the date acquired for each scene was listed on the Web site, we discovered these were inaccurate. This required us to obtain the flight line records from the state contractor. Furthermore, the images were not time stamped and acquisition times were not recorded in the metadata. This required us to locate conspicuous shadows from vertical structures (trees, poles, towers and buildings) and to estimate the solar angle like a sundial. Given the acquisition date, the latitude and the longitude of each structure, solar noon was determined using NOAA's Solar Calculator (http://www.esrl.noaa.gov/gmd/ $\mathrm{grad} / \mathrm{solcalc} /$ ). Each $0.25^{\circ}$ angular offset from solar noon represents $\pm 1 \mathrm{~min}$ (Weishampel and Urban, 1996), which enables the time of day estimate. This methodology to determine acquisition time was tested on historic date- and time-stamped aerial images and were accurate to $\pm 20 \mathrm{~min}$.

\section{Delineation of inundated areas using remote sensing data}

A change detection approach was adopted to detect inundated pixels as result of the change in water level. The method consists of comparing two Radarsat 1 (SAR) images that cover the same scene but acquired on two different dates with similar radar configurations. The image that corresponds to the lowest water level is considered as reference image. The second image corresponds to the studied scene that was acquired when the sea level was higher. Figure 3 shows the flowchart adopted to implement the proposed methodology.

Image preprocessing. The main difficulty when using active microwave images is the reduction of the inherent speckle noise in the radar backscatter. This noise reduces the contrast between land and sea surfaces and therefore limits the potential of detecting flooded areas from radar images. The application of appropriate filters was necessary to reduce the noise in the obtained images and to allow for a better identification of inundated areas. Several filters such as the mean, median, Lee's local statistics, sigma, the Kuan, the Maximum a posteriori probability and the Frost filters are widely used. Lopes et al. (1990) proposed the enhanced Lee filter due to its preservation of the edges between different areas. Compared with most well-known filters, Frost, Kuan and Lee filters seem to perform better in this respect (Lopes et al., 1990). The speckle filtering is applied using a moving window of fixed size. As the window size increases, the speckle noise decreases. For a four look image, $3 \times 3,5 \times 5$ and $7 \times 7$ pixels window sizes are considered in the literature (Lee, 1981; Lee, 1986; Lopes et al., 1990; Touzi, 2002). To improve the speckle reduction capability, most of the adaptive speckle filters can be run several times to reach an acceptable level of noise reduction. In this study, we applied the enhanced Lee filter three times using a window size of $5 \times 5$.

The filtered Radarsat images were then coregistered with the Landsat 7 bands 4, 3 and 2 RGB composite image using 17 control points. The nearest neighbour interpolation method was applied to maintain the grey levels of each image. The resulting root mean square error (RMSE) from the coregistration of Radarsat is 0.37 , which corresponds to $4.625 \mathrm{~m}$ in the images.

Delineation of the flood-prone area. A preliminary analysis of the radar scenes shows a significant spatial variability in the backscatter values. Water should appear black in radar images as its backscatter should be close to zero. However, wind effects increase the roughness of the water surface and cause the water surface to produce backscatter values close to those of land pixels. In inland areas, the change in land cover also affects the spatial 


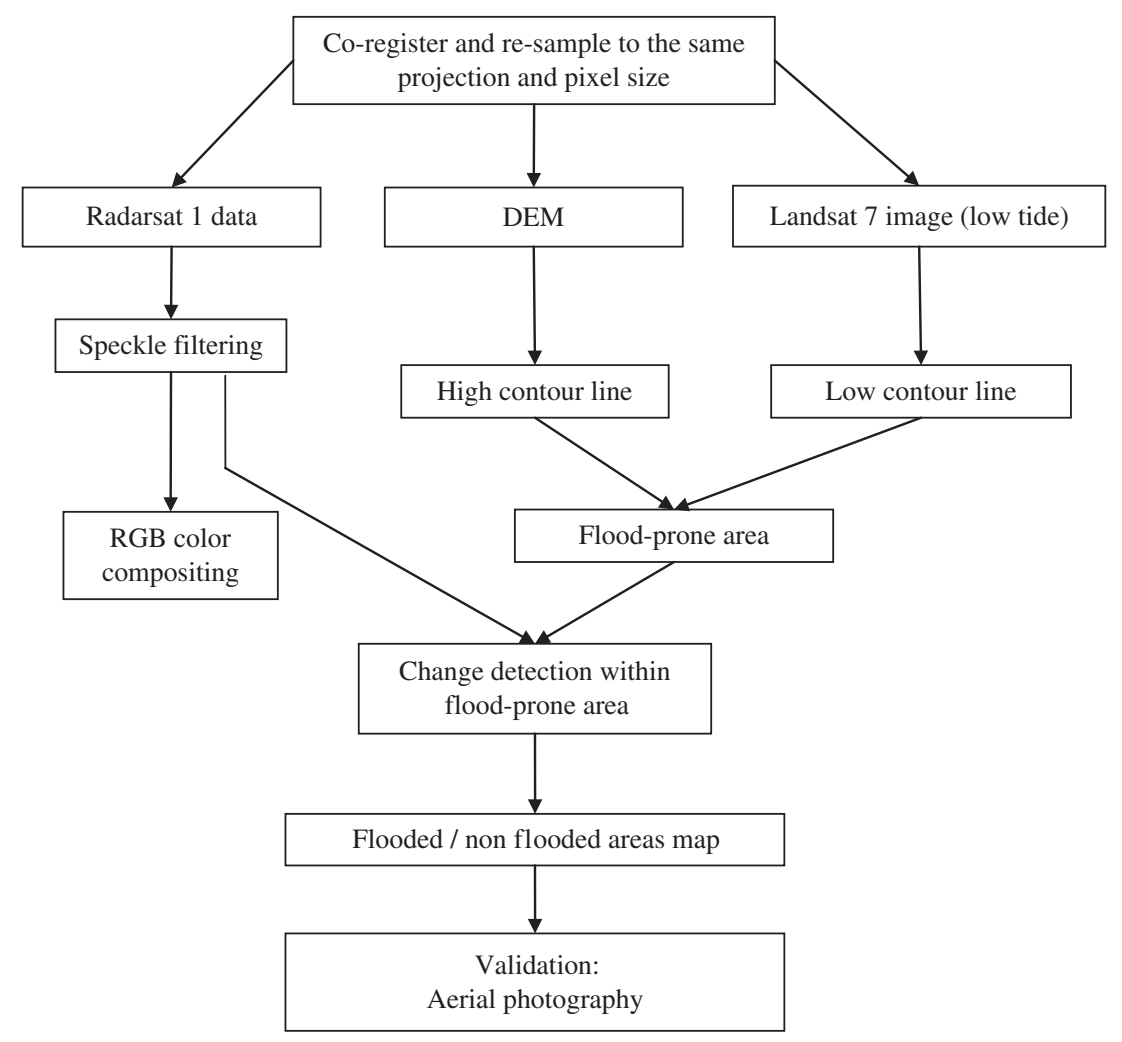

Figure 3. Flowchart of coastal flooded areas determination approach

variability of the backscatter and may lead to a potential overlap between water and land pixels in terms of backscatter ranges. The distinction between water and land classes on the basis of the use of the entire scene is, therefore, not straightforward.

To minimize the misclassification of the radar image, we propose using ancillary data to define the flood-prone area a priori through the determination of two contour lines corresponding to the extreme low and high water conditions. Low water level marks were obtained from Landsat 7 images acquired under lower tide conditions, and the DEM was used to determine the higher contour line.

The higher contour corresponds to the highest water level recorded between the acquisition dates of the first and the last Radarsat images that are used in this study. This high water level was set to $0.82 \mathrm{~m}$. The image, or more precisely the NIR channel that corresponds to Landsat 7 band 4, was classified and water extent was identified. Hence, the determination of lower and higher contour lines substantially increased the efficiency of the flood-prone area delineation. The analysis of the backscatter and the detection of the change between the scenes should be done within the defined flood-prone area. It is expected that the restriction of the analysis of the radar backscatter to the determined area should improve the performance of the classification technique and help to accurately determine the actual extent of inundated areas in coastal regions.

Determination of flooded areas. A multitemporal image enhancement technique was applied to determine the inundated areas along the coast. This technique assigns the red, green and blue colours to two different black and white SAR images acquired in two different conditions. One of the two images illustrates low tide condition and was assigned a red colour (i.e. reference image), and the second image corresponds to the high tide event and was assigned the green and blue colours. The hue of the colour in the multitemporal false colour composite obtained image indicates the date of the change, whereas the intensity of the colour represents the degree of change (Kiage et al., 2005). The red colour in the RGB composite corresponds to flooded areas, whereas unchanged areas appear in white colour. Cyan colour corresponds to a negative change. The colour compositing is, in this regard, invaluable to visually identifying the segment of the image that was subject to change with respect to the conditions in the reference image.

Coastal inundation maps are developed within the predetermined flood-prone area through the analysis of the frequency distribution of the grey levels in each image. The problem of identifying flooded areas becomes analogous to the problem of threshold determination. Because the class of flooded areas corresponds to the lowest amplitude values, the appropriate threshold for the first class should be selected at the valley between the first and the second peak of the histogram.

\section{RESULTS AND DISCUSSION}

The analysis of the RGB colour compositing using the full scene of two Radarsat 1 images acquired under two 
different tide conditions shown in Figure 4 revealed the presence of red zones along the coast, in open water and inland. These red areas refer to the decrease in the radar signal during high tide condition. Cyan colour refers to an increase in the backscatter value during high tide condition. White coloured areas correspond to unchanged areas

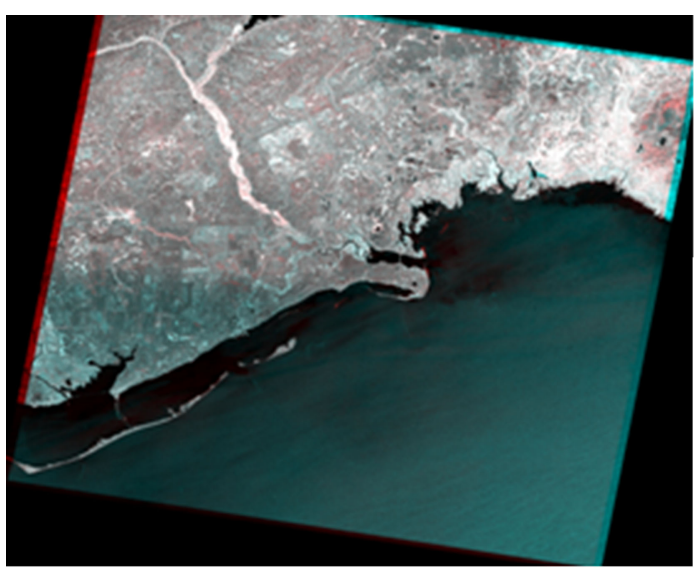

$01 / 20 / 2003$

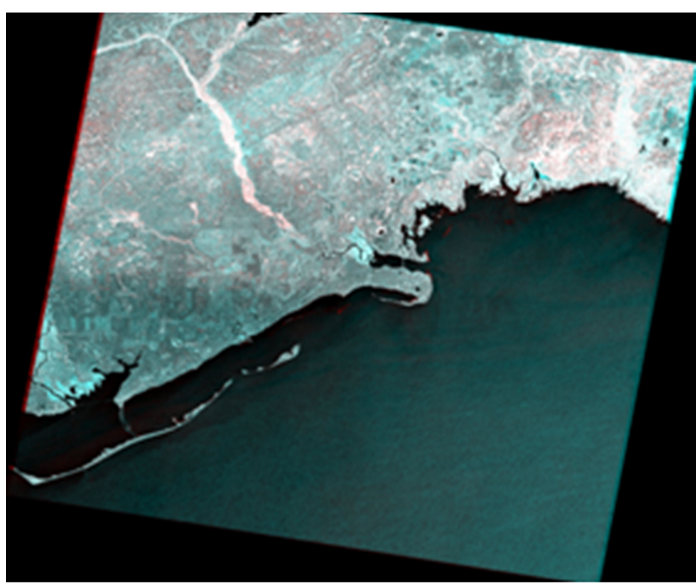

$09 / 17 / 2003$

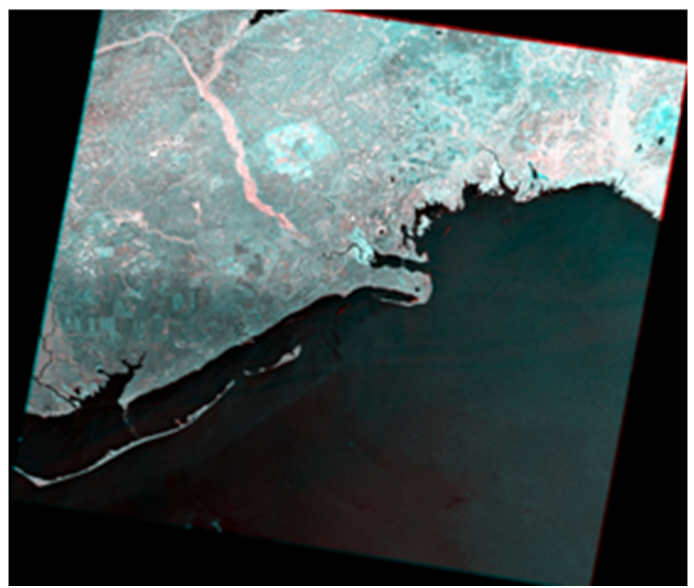

$07 / 25 / 2004$

Figure 4. RGB colour composting using full scene Radarsat 1 images; cyan colour: increase on backscatter value on mentioned dates; red colour: decrease on backscatter value; and white colour: unchanged areas (Radarsat 1 data taken on 3 March 2004, low tide condition, is considered as initial state) between the two acquisition dates. Because both images were taken with the same radar configuration, the difference in backscatters can only be caused by changes in vegetation structure, ground surface roughness or dielectric constant of the soil, which is function of soil moisture.

As the soil gets wet, the dielectric constant and subsequently the backscatter intensity increase. The increase in surface roughness also increases the backscattered signal. When the rough surface becomes wet, the return signal increases because of a higher dielectric constant while it decreases when the rough bare soil becomes flooded. The inland land cover is characterized primarily by the presence of evergreen forests and woody wetlands. In these areas, the backscattered signal depends on the size, shape, density and the dielectric constant of the vegetation. As biomass increases, the backscatter value increases. Live vegetation with high water content has a high dielectric constant, whereas dead vegetation has lower water content and therefore a lower dielectric constant. In fact, the RGB colour compositing image of 20 January 2003 appears darker (i.e. decrease in backscatter) than those corresponding to September 2003 and July 2004. Typically, in July and September, the vegetation is well developed, showing an increase in the backscatter. In dry condition typical of January in this region, sparse vegetation exhibits low backscatter values that increase as the soil gets wet. When the soil is flooded, its backscatter is lower than that of dry soil (Kasischke and Bourgeau-Chavez, 1997; Kasischke et al., 2003; Martinez and Le Toan, 2007). For a better identification of flooded areas, the preidentification of inland changed areas is then necessary to exclusively consider inundation-caused change.

Figure 4 shows red areas (i.e. decrease in backscatter) in the open water as well. This decrease in backscatter can be confused with inundated areas along the coast as they both display similar backscatter values. This can be explained by the fact that the backscatter from the wind-roughened and wave-modulated water can be equal or exceed the response from the flooded areas (Bourgeau-Chavez et al., 2005). Indeed, the RGB compositing image of September 2003 shows an increase in backscatter value (cyan colour) in the open water due to the increase of the surface roughness. The wind speed on 9 September 2003 exceeds the wind speed registered on 3 March 2004 (Table I). Smooth water surfaces reflect the energy in a specular manner and appear black in the image. This corroborates the conclusions of Nico et al. (2000), who recommended the preidentification and elimination of open water from the radar scenes before the determination of inundated pixels.

Along the coast, the variation in the radar signal was mainly caused by the dynamic wetting front caused by tidal fluctuations. When sea water recedes during low tide, the exposed soil is saturated with water, but its backscattered response is different from the one obtained when it was flooded. The presence of vegetation can also alter the backscattered response from wet soils. The vegetation effect depends on the vegetation type (mainly its height and density). However, along the coast, the vegetation is 
usually classified into either emergent herbaceous wetlands or woody wetlands. These land cover types should have a minimal effect in the backscattered signal. The variation of biomass in a vegetation layer with relatively low canopies, low biomass and small stem sizes has little effect on the backscatter values (Kasischke et al., 2003). Flooded marshes in the radar scenes (Figure 4) show low backscatter values (red areas), suggesting that the $\mathrm{C}$ band signal was reflected away which is in line with previous findings (Tanis et al., 1994; Kasischke et al., 2003; Bourgeau-Chavez et al., 2005). Hence, soil moisture and water level represent the dominating factors that affect the radar signal in the study zones.

Figure 5 shows the obtained flood-prone area contained between the two envelope lines that correspond to the DEM contour line (the higher contour) and the position of the wetting front in the low tide Landsat image (the lower contour). It also shows the result of the RGB colour composited images using one Radarsat image taken on 3 March 2004 as reference image as it corresponds to low tide conditions. Three different images taken on 20 January 2003, 17 September 2003 and 25 July 2004 were used to generate the RGB composite. We assume that the geomorphology of the land features did not change between the acquisition dates as we are compositing images acquired on different dates. The water level was the highest on 25 September 2004. The relative difference between the RGB scenes is not perceptible in Figure 5 because their extent is larger than the scale of change in the wetting front as the water level varies. Further validations presented herein with local aerial photography can accurately assess the difference between the images. Within the flood-prone area, the red colour indicates inundated areas during the high tide condition. A graduation in the red colour can be seen in the three scenes. The intensity of the colour represents the magnitude of the flood, which is proportional to the degree of change in the backscattered signal. Near the shore, and particularly along the Barrier Islands, the red colour is more intense. The intensity of the red colour decreases farther inland. With respect to the RGB composite shown in Figure 4, the red colour was more discernible than in Figure 5 when only the flood-prone area was displayed. Hence, the predetermination of the flood-prone area allows for a better identification of the extent of the wetting front as it enhances the contrast between dry, wet and flooded soils. The analysis of the histograms of the different studied scenes shown in Figure 6 illustrates this finding.

Figure 6 represents the distribution of the amplitude values considering (i) the entire radar scene and (ii) the flood-prone area. The restriction of the study area to the flood-prone area clearly reduced the number of classes in the image and led to a better classification of each image. Different classes can be distinguishable between low (image taken on 3 March 2004) and high (images taken on 1 January 2003, 17 September 2003 and 25 July 2004) tide condition images. For both conditions, the lower amplitude value, first class, is expected to correspond to the flooded areas as inundated areas should have lower

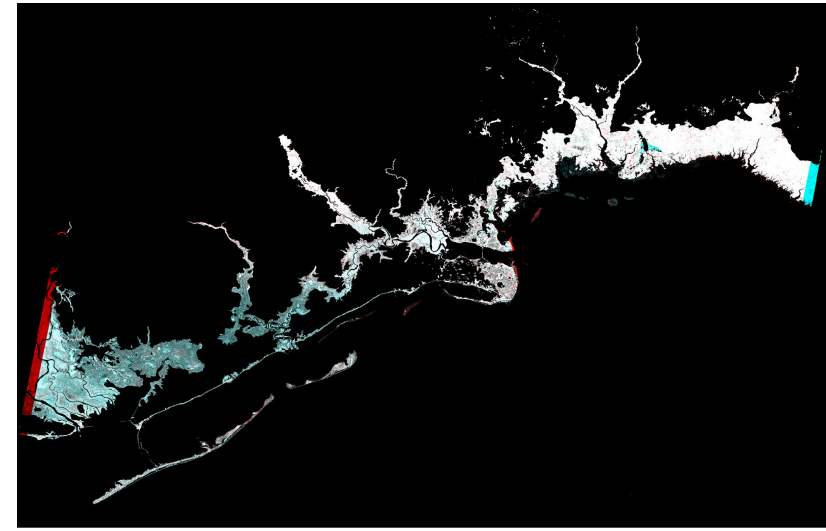

$01 / 20 / 2003$

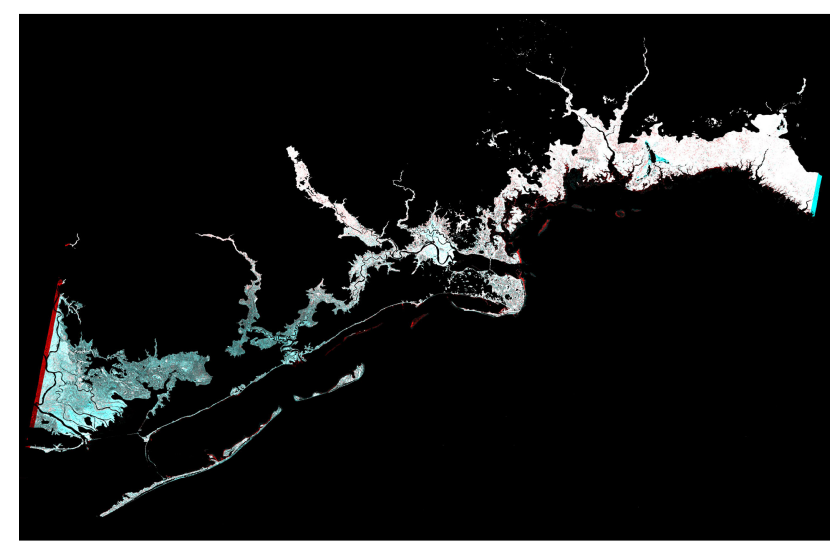

$09 / 17 / 2003$

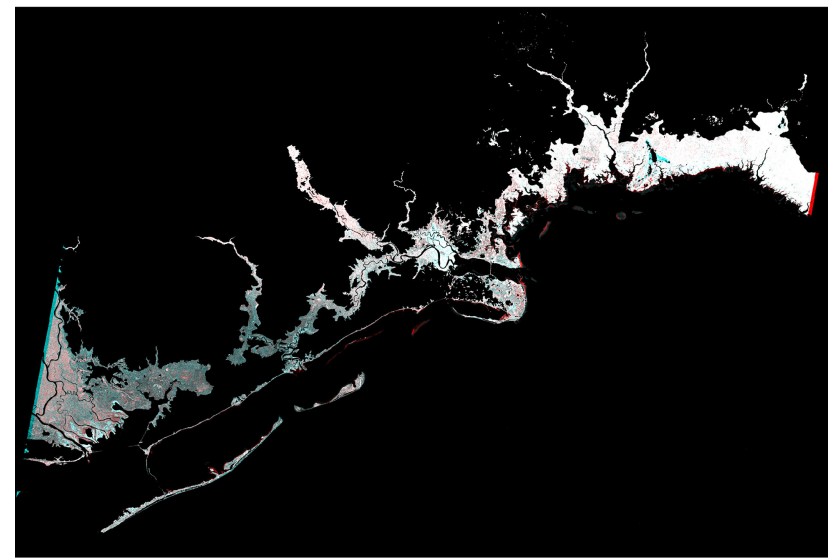

$07 / 25 / 2004$

Figure 5. RGB colour compositing within intertidal zone agreement; cyan colour: increase on backscatter value on mentioned dates; red colour: decrease on backscatter value; and white colour: unchanged areas (Radarsat 1 data taken on 3 March 2004, low tide condition, is considered as initial state)

backscatter. Flooded area extraction is equivalent to the first class threshold estimation problem using the histogram.

Inundation map extraction is based on the determination of different thresholds corresponding to flooded areas in each image and each tide condition. Threshold determination using histograms depends on the frequency distribution of the grey levels of the images. Histograms presenting the amplitude distribution within the floodprone area show better differentiation between different 

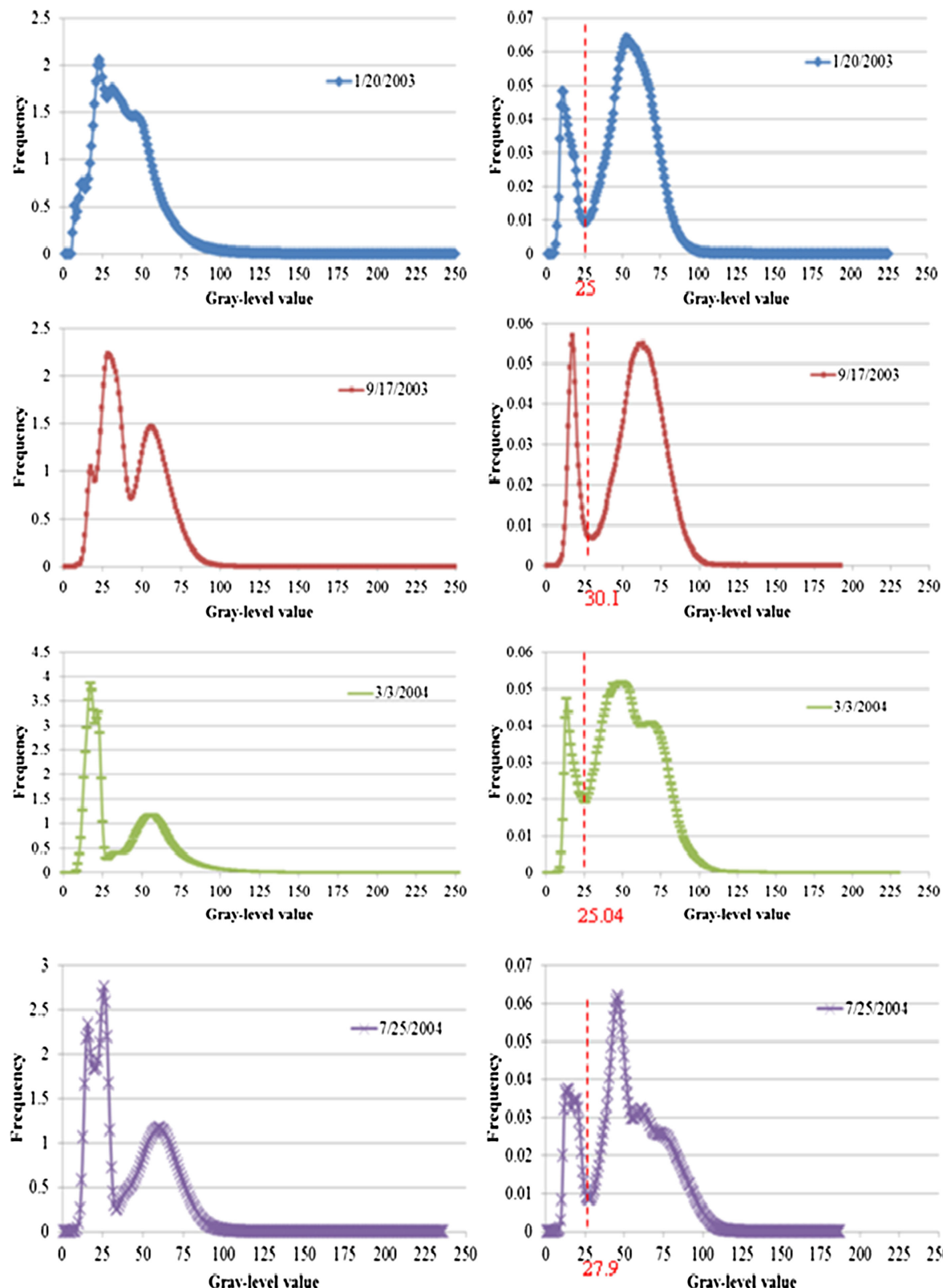

(a) Fullscene

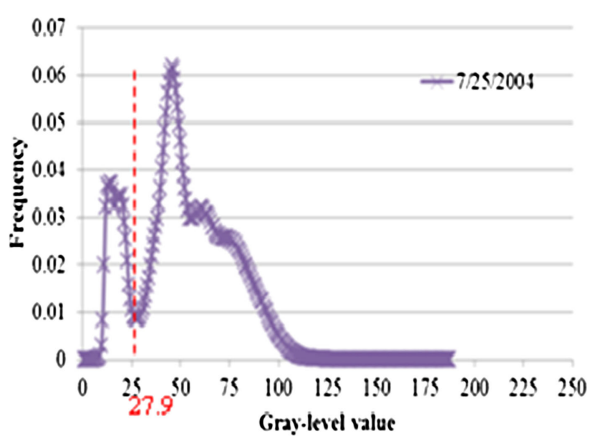

(b) Within flood-prone area

Figure 6. Gray level histograms. Red values: selected thresholds

classes with respect to histograms developed from entire scene. In fact, the histogram within this area presents a deeper valley between different classes (Figure 6). In this case, the appropriate threshold value is selected at the bottom of the first valley. In the case of the full image, the determination of the separator between the classes is not as straightforward because the histogram presents peaks of different sizes separated by a broad valley as shown in Figure 6.

The classification of each image within the flood-prone area leads to the delineation of inundated zones. Regardless of the tide conditions and the water level associated with those conditions, the value of the backscatter threshold seems to be consistent amongst the different histograms. A mean threshold value of 27.01 with a standard deviation of 2.47 is obtained from the histograms.
The difference between inundation maps generated from different tide conditions shows an agreement with the changed areas identified in red in the RGB colour composited images. Figure 7 shows obtained inundation maps using the data taken on 03 March 2004 as a reference image.

To assess the consistency of the obtained inundation extent, we compared the number of pixels classified as flooded with the observed water level at each tide condition in Figure 8. A positive correlation was observed. The higher the water level, the larger is the flood zone. A linear trend with an $R^{2}$ value of 0.83 is obtained. Considering the 12.5-m spatial resolution of radar scenes and the number of pixels that are inundated between $-0.2 \mathrm{~m}$ (low tide) and $+0.3 \mathrm{~m}$ (high tide), which is approximately 110,000 pixels $(490,000-380,000)$, one can conclude that approximately 

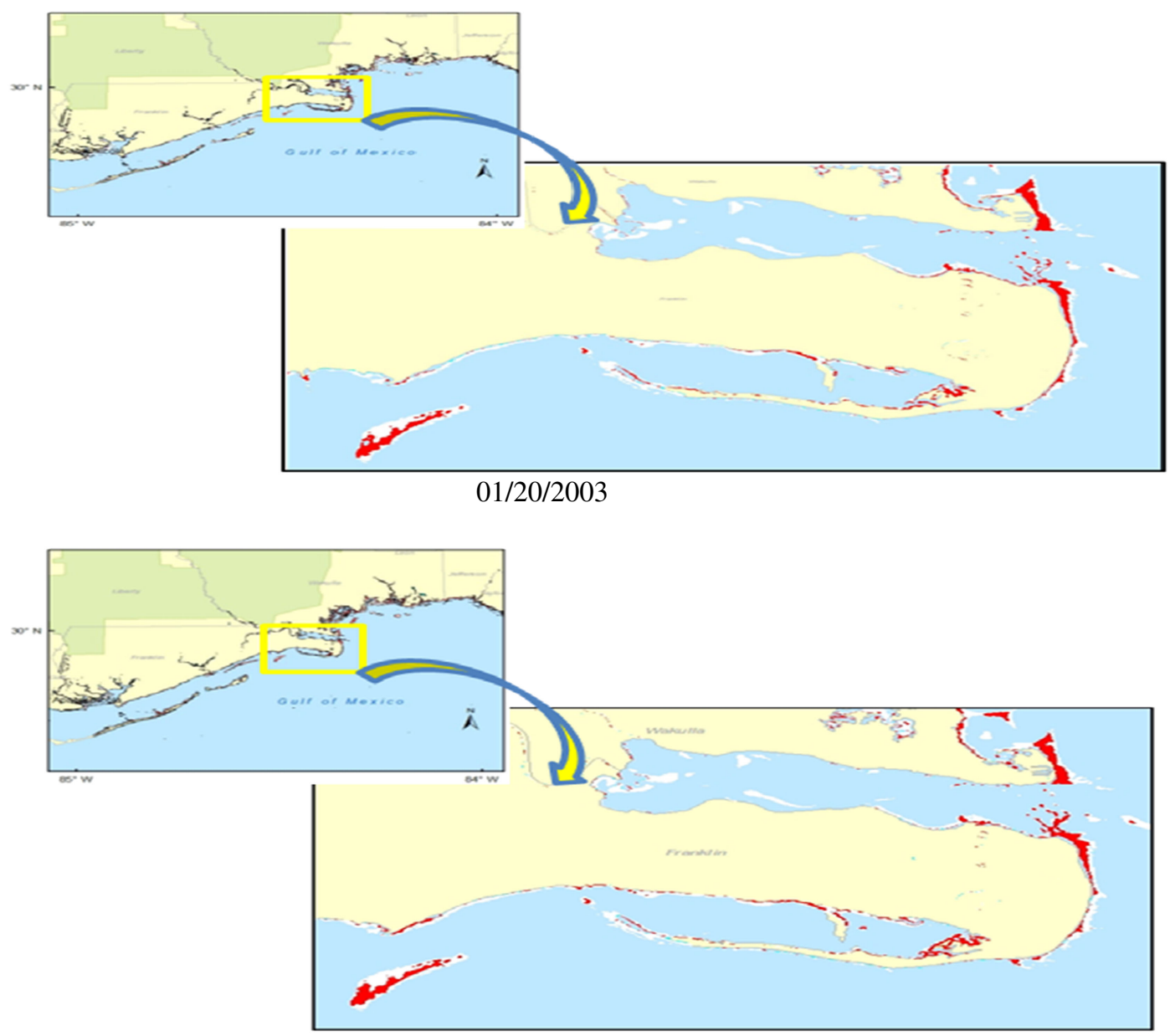

$09 / 17 / 2003$

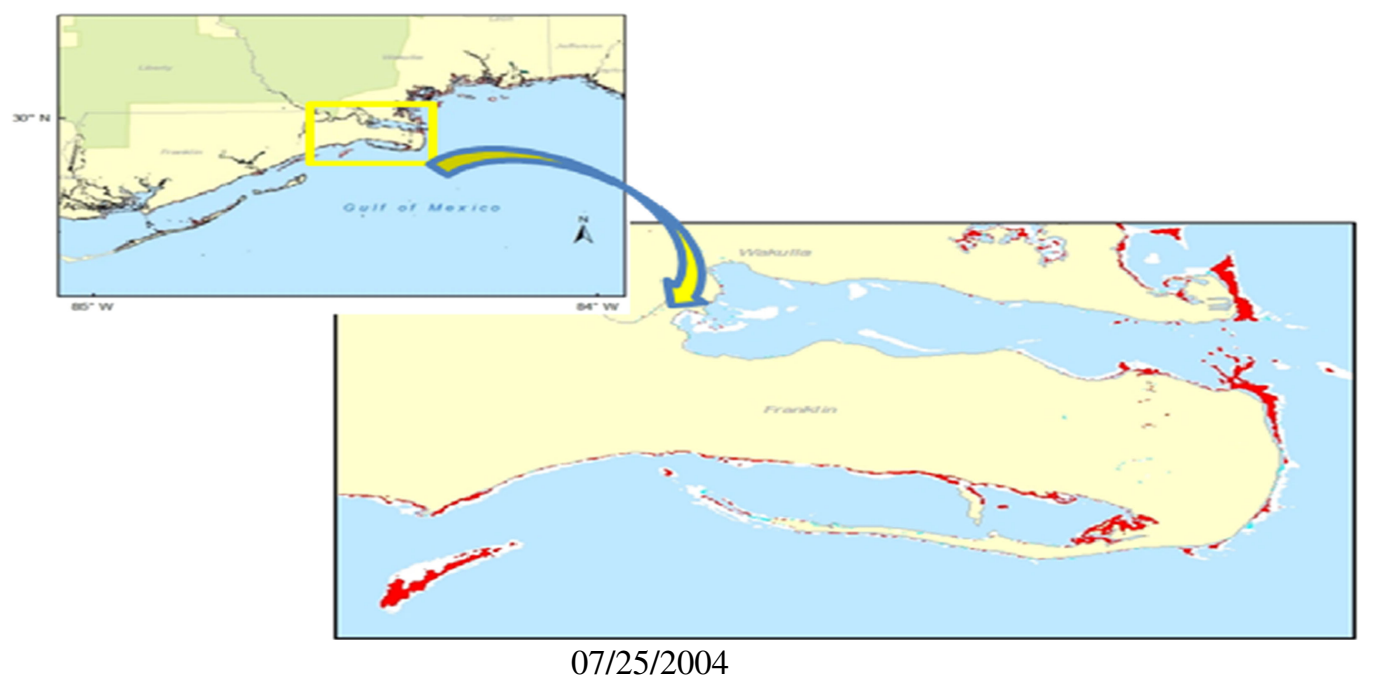

Figure 7. Flooded area maps

$17 \mathrm{~km}^{2}$ are inundated in the entire scene. This suggests that this particular coastal area is sensitive to water level fluctuations. The linear relationship can be exploited further in the framework of climate change scenarios to assess the effects of sea level rise.

The image classification results and the coastal flood mapping algorithm were tested using aerial photography taken over specific sections of the flood-prone area. Figure 9 shows flooded pixels delineated with the radar data taken on 3 March 2004 and two aerial photographs, which were taken over specific sites with the study area. Water extent in the aerial photographs was identified visually. Water levels when the radar and the aerial photographs were taken were comparable. Green colour 


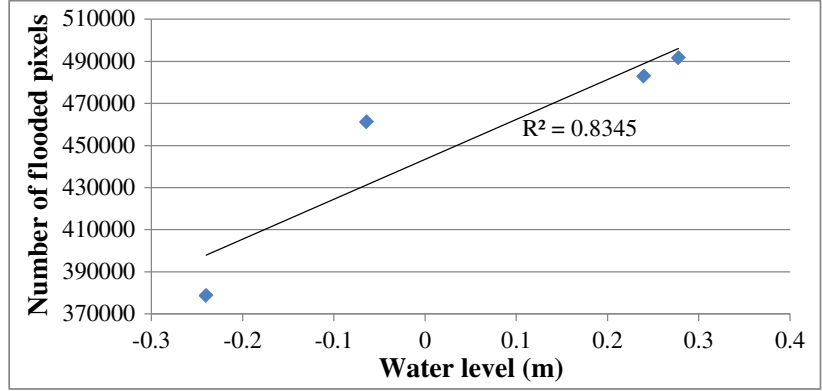

Figure 8. Relationship between water level and number of flooded pixels corresponds to pixels identified as flooded with both data sources. Yellow colour corresponds to flooded pixels identified with only radar data, whereas blue colour corresponds to flooded pixels identified with only the aerial photographs. For each zone, a good agreement can be seen. The difference between inundation maps generated from radar and aerial images can be explained by the difference in the corresponding observed water level (Table II). Radar data correspond to the lowest observed water level (see Table I), leading to fewer flooded pixels.

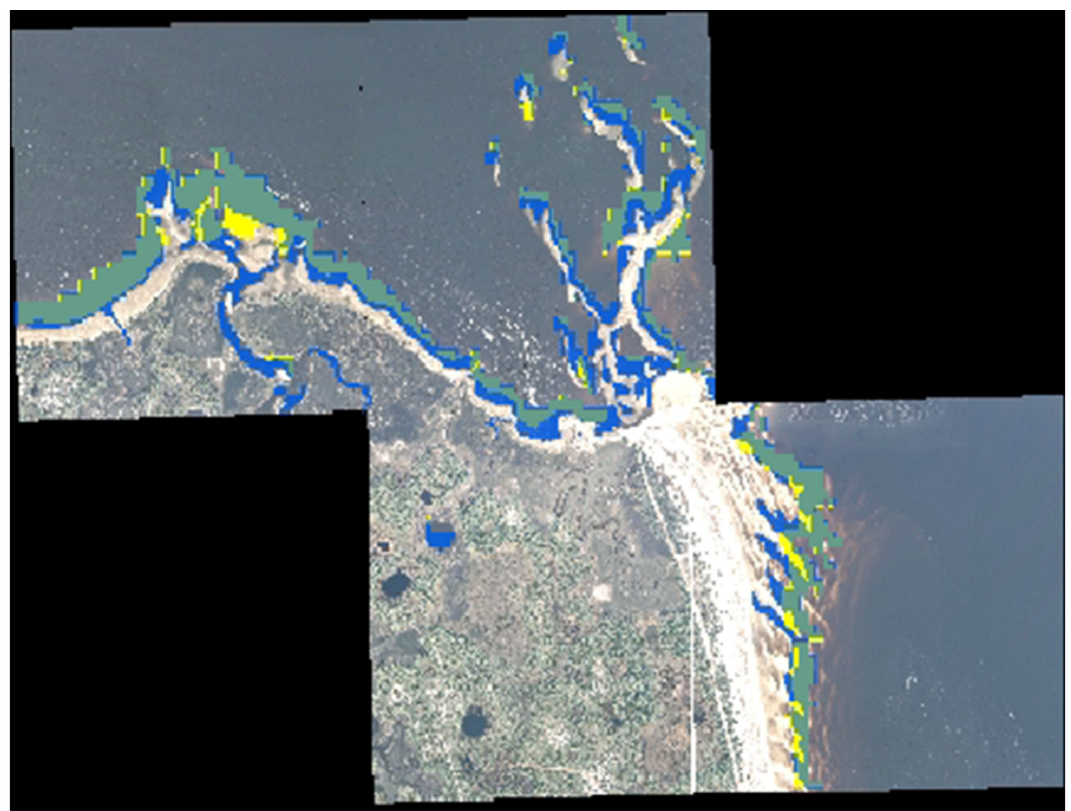

(Site1)

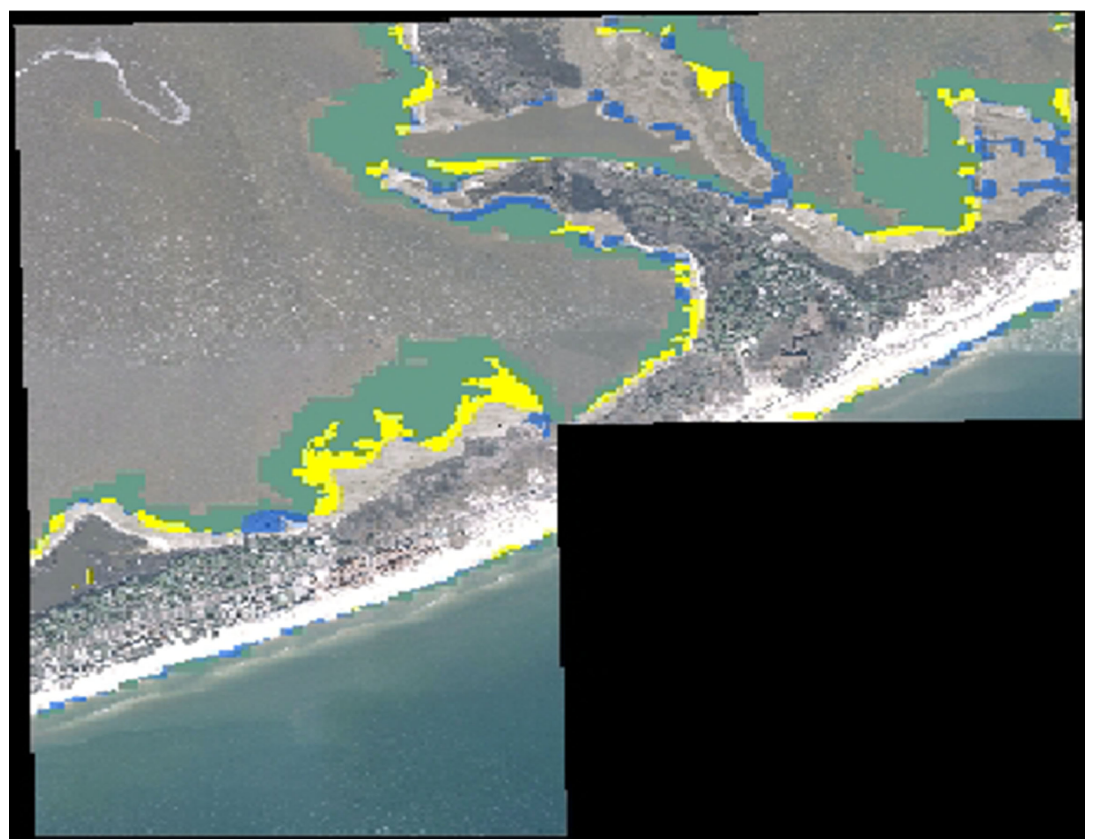

(Site 2)

Figure 9. Comparaison of flooded areas maps with aerial photos (green colour: flooded areas detected with both radar and aerial photo; yellow colour: flooded areas detected with radar only; blue colour: flooded area detected with the aerial photo only) 
Table II. POD values for flooded pixels class

\begin{tabular}{lcc}
\hline & Site 1 & Site 2 \\
\hline Water level $(\mathrm{m})$ & -0.184 & -0.222 \\
POD $(\%)$ & 58 & 83.8 \\
\hline
\end{tabular}

To evaluate the agreement between inundation extent derived from radar data and aerial photography (considered here as 'truth data'), we calculated the probability of detection (POD) of flooded pixels (Marzban, 1998; Williams et al., 2002):

$$
\mathrm{POD}=A /(A+C)
$$

where $A$ is the number of pixels of class $\mathrm{X}$, which have been correctly classified as class $\mathrm{X} ; C$ is the number of pixels of class $X$, which have not been classified as $X$; and $X$ is the flooded pixels class.

The POD values in Table II show that the flooded pixels were better detected in site 2 with a POD exceeding $80 \%$. For site 1 , the POD is equal to $58 \%$. The latter can be explained by the fact that the corresponding observed water level is lower than the water level observed when the radar image was taken. This difference increased the discrepancy between the images and led to a significant misclassification of flooded pixels in site 1 , where more flooded pixels in the aerial photograph were classified as non flooded pixels with the radar data.

\section{CONCLUSIONS}

A change detection approach was developed to detect inundated areas in the coastal region of the northern Gulf of Mexico using Radarsat 1 images. The determination of flooded area is carried out using a multitemporal image enhancement technique. This technique revealed the presence of flooded areas along the coast, in open water and inland through the detection of changes in backscatter.

The RGB colour compositing method can be used for the visualisation of the change between low and high tide conditions. However, the extraction of the flooded areas map that can be integrated straightforwardly into different software is necessary. The predetermination of the floodprone area using two contour lines corresponding to the extreme low and high water conditions from Landsat images acquired under appropriate conditions and the elevation data allows for better classification of the radar image and the detection of the inundated areas in the coastal zone. Image segmentation is best obtained by thresholding the flood-prone area histograms. The distribution of the grey levels of the images within these areas present distinguishable classes.

For intertidal flooding studies, the preidentification of the flood-prone area allows for a better identification of inundated areas. Within this area, the wetting/drying front determination is more straightforward and fewer spurious results are introduced into the results. Accurate Radarsat coregistration and speckle noise removal also improve the results. The results of this study can be used to validate or initialize hydrodynamic coastal models by providing researchers with spatially and temporally known conditions. Because many coastal inundation models are designed to hindcast hurricane storm surge events, the availability of this type of data is limited because optical sensors are rendered ineffective in the presence of large swaths of cloud cover. The use of SAR data for this purpose will enable researchers to compare their simulated inundation extents with those that actually occurred during the subject event.

\section{REFERENCES}

Badji M, Dautrebande S. 1997. Characterization of flood inundated areas and delineation of poor drainage soil using ERS-1 SAR imagery. Hydrological Processes 11(10): 1441-1450.

Bazi Y, Bruzzone L, Melgani F. 2005. An unsupervised approach based on the generalized Gaussian model to automatic change detection in multitemporal SAR images. IEEE Transactions on Geoscience and Remote Sensing 43(4): 874-887.

Bonn F, Dixon R. 2005. Monitoring Flood Extent and Forecasting Excess Runoff Risk with RADARSAT-1 Data. Natural Hazards 35(3): 377-393.

Bourgeau-Chavez LL, Kasischke ES, Brunzell SM, Mudd JP, Smith KB, Frick AL. 2001. Analysis of space-borne SAR data for wetland mapping in Virginia riparian ecosystems. International Journal of Remote Sensing, Taylor \& Francis Ltd. 22: 3665-3687.

Bourgeau-Chavez L, Smith K, Brunzell S, Kasischke E, Romanowicz E, Richardson C. 2005. Remote monitoring of regional inundation patterns and hydroperiod in the Greater Everglades using Synthetic Aperture Radar. Wetlands 25(1): 176-191.

Bovolo F, Bruzzone L. 2005. A detail-preserving scale-driven approach to change detection in multitemporal SAR images. IEEE Transactions on Geoscience and Remote Sensing 43(12): 2963-2972.

Brivio PA, Colombo R, Maggi M, Tomasoni R. 2002. Integration of remote sensing data and GIS for accurate mapping of flooded areas. International Journal of Remote Sensing 23(3): 429-441.

Cihlar J, Pultz TJ, Gray AL. 1992. Change detection with synthetic aperture radar. International Journal of Remote Sensing 13(3): 401-414.

Dekker RJ. 1998. Speckle filtering in satellite SAR change detection imagery. International Journal of Remote Sensing 19(6): 1133-1146.

Dey C, Jia X, Fraser D. 2008. Decision fusion for reliable flood mapping using remote sensing images, Canberra, Australia. Inst. of Elec. and Elec. Eng: Computer Society.

Hess LL, Melack JM, Filoso S, Yong W. 1995. Delineation of inundated area and vegetation along the Amazon floodplain with the SIR-C synthetic aperture radar. IEEE Transactions on Geoscience and Remote Sensing 33(4): 896-904.

Homer C, Dewitz J, Fry J, Coan M, Hossain N, Larson C, Herold N, McKerrow A, VanDriel JN, Wickham J. 2007. Completion of the 2001 National Land Cover Database for the Conterminous United States. Photogrammetric Engineering and Remote Sensing 73(4): 337-341.

Kasischke ES, Bourgeau-Chavez LL. 1997. Monitoring South Florida wetlands using ERS-1 SAR Imagery. Photogrammetric Engineering and Remote Sensing 63(3): 281-291.

Kasischke ES, Smith KB, Bourgeau-Chavez LL, Romanowicz EA, Brunzell S, Richardson CJ. 2003. Effects of seasonal hydrologic patterns in south Florida wetlands on radar backscatter measured from ERS-2 SAR imagery. Remote Sensing of Environment 88(4): 423-441.

Kiage LM, Walker ND, Balasubramanian S, Babin A, Barras J. 2005. Applications of Radarsat-1 synthetic aperture radar imagery to assess hurricane-related flooding of coastal Louisiana. International Journal of Remote Sensing 26(24): 5359-5380.

Kwoun O-I, Lu Z. 2009. Multi-temporal RADARSAT-1 and ERS backscattering signatures of coastal wetlands in southeastern Louisiana. Photogrammetric Engineering and Remote Sensing 75(5): 607-617.

Lee J-S. 1981. Refined filtering of image noise using local statistics. Computer graphics and image processing 15(4): 380-389.

Lee J-S. 1986. Speckle suppression and analysis for synthetic aperture radar images. Optical Engineering 25(5): 636-643. 
Li J, Chen W. 2005. A rule-based method for mapping Canada's wetlands using optical, radar and DEM data. International Journal of Remote Sensing 26(22): 5051-5069.

Lopes A, Touzi R, Nezry E. 1990. Adaptive speckle filters and scene heterogeneity. IEEE Transactions on Geoscience and Remote Sensing 28(6): 992-1000.

Macri-Pellizzeri T, Oliver CJ, Lombardo P. 2002. Segmentation-based joint classification of SAR and optical images. IEE Proceedings-Radar Sonar and Navigation 149(6): 281-296.

Martinez JM, Le Toan T. 2007. Mapping of flood dynamics and spatial distribution of vegetation in the Amazon floodplain using multitemporal SAR data. Remote Sensing of Environment 108(3): 209-223.

Martinis S, Twele A, Voigt S. 2009. Towards operational near real-time flood detection using a split-based automatic thresholding procedure on high resolution TerraSAR-X data. Natural Hazards and Earth System Sciences 9(2): 303-314.

Marzban C. 1998. Scalar measures of performance in rare-event situations. Weather and Forecasting 13(2): 753-763.

Matgen P, Hostache R, Schumann G, Pfister L, Hoffmann L, Savenije HHG. 2011. Towards an automated SAR-based flood monitoring system: Lessons learned from two case studies. Physics and Chemistry of the Earth, Parts A/B/C 36(7-8): 241-252.

Nico G, Pappalepore M, Pasquariello G, Refice A, Samarelli S. 2000. Comparison of SAR amplitude vs. coherence flood detection methods-a GIS application. International Journal of Remote Sensing 21(8): 1619-1631.

Pohl C, Van Genderen JL. 1998. Multisensor image fusion in remote sensing: concepts, methods and applications. International Journal of Remote Sensing 19(5): 823-854.

Rango A, Salomonson VV. 1974. Regional flood mapping from space. Water Resources Research 10(3): 473-484.

Schumann G, Bates PD, Horritt MS, Matgen P, Pappenberger F. 2009. Progress in integration of remote sensing-derived flood extent and stage data and hydraulic models. Reviews of Geophysics 47(4): RG4001.

Solberg AHS, Jain AK, Taxt T. 1994. Multisource classification of remotely sensed data: Fusion of Landsat TM and SAR images. IEEE Transactions on Geoscience and Remote Sensing 32(4): 768-778.
Sun Y, Li X, Gong H, Zhao W, Gong Z. 2007. A study on optical and SAR data fusion for extracting flooded area. International Geoscience and Remote Sensing Symposium, Barcelona, Spain; 3086-3089.

Tanis FJ, Bourgeau-Chavez LL, Dobson MC. 1994. Application of ERS-1 SAR for coastal inundation. International Geoscience and Remote Sensing Symposium, Pasadena, California, USA; 1481-1483.

Tholey N, Clandillon S, DeFraipont P. 1997. The contribution of spaceborne SAR and optical data in monitoring flood events: Examples in northern and southern France. Hydrological Processes 11(10): 1409-1413.

Touzi R. 2002. A review of speckle filtering in the context of estimation theory. IEEE Transactions on Geoscience and Remote Sensing 40(11): 2392-2404.

Townsend PA. 2001. Mapping seasonal flooding in forested wetlands using multi-temporal radarsat SAR. Photogrammetric Engineering and Remote Sensing 67(7): 857-864.

Toyra J, Pietroniro A. 2005. Towards operational monitoring of a northern wetland using geomatics-based techniques. Remote Sensing of Environment 97(2): 174-191.

Toyra J, Pietroniro A, Martz LW, Prowse TD. 2002. A multi-sensor approach to wetland flood monitoring. Hydrological Processes 16(8): 1569-1581.

Wang Y. 2002. Mapping extent of floods: What we have learned and how we can do better. Natural Hazards Review 3(2): 68-73.

Wang Y, Hess LL, Filoso S, Melack JM. 1995. Understanding the radar backscattering from flooded and nonflooded amazonian forests: Results from canopy backscatter modeling. Remote Sensing of Environment 54(3): 324-324.

Wang Q, Watanabe M, Hayashi S, Murakami S. 2003. Using NOAA AVHRR data to assess flood damage in China. Environmental Monitoring and Assessment 82(2): 119-148.

Weishampel JF, Urban DL. 1996. Coupling a spatially-explicity forest gap model with 3-D solar routine to simulate latitudinal effects. Ecological Mcodelling 86: 101-111.

Williams RN, Michael KJ, Pendlebury S, Crowther P. 2002. An automated image analysis system for determining sea-ice concentration and cloud cover from AVHRR images of the Antarctic. International Journal of Remote Sensing 23(4): 611-625. 